\title{
Erteleme: Türleri, Bileşenleri, Demografik Etkenler ve Kültürel Farklılıklar
}

$$
\text { Bilge UZUN }{ }^{1} \quad \text { Ayhan DEMIR }{ }^{2}
$$

Geliş Tarihi: 07.03.2015 Kabul Tarihi: 20.05.2015

\section{Öz}

Yapılması planlanan iş ve görevlerin ileriki bir zamana bırakılıp ötelenmesi erteleme olarak adlandırılır (Lay, 1986). Erteleme sonucunda kişi iş ve görevlerini ileriki bir zamana bıraktığı için geçici bir süre rahatlamış olmasına rağmen, bu eğilimin davranışa dönüşmesi çoğu zaman stres artışı, organizasyon bozukluğu ve başarısızlık ile sonuçlanır. Ertelemenin altında yatan 'daha sonra daha iyi' düşüncesi olsa da, ertesi gün geldiğinde örüntü yinelenir ve kişi kendisine 'bunu yarın yapacağım' sözü verir. Bu nedenle erteleme 'ertesi gün sendromu' olarak da adlandırılabilir. Araştırma bulguları, ertelemenin olumsuz sonuçlara neden olduğunu ve bu durumun kişinin psikolojik iyilik halini etkileyebildiğini ortaya koyduğundan, ertelemenin önlenmesinin gerekli olduğuna dikkat çekmektedir. Ülkemizde de ertelemeyi ele alan çalışmalar dünya alan yazınını takip eder durumdadır. Bulgular, ülkemizde de ertelemenin yaygınlığını ortaya koyarken bu davranışın iyileştirilmesinin önemini göstermektedir. Bu doğrultuda, bu derleme çalışmasında, ertelemenin farklı yönleri ile anlaşılması amacı ile ertelemeye ilişkin tanımlar, ertelemenin türleri ve bileşenlerine yer verilirken; erteleme davranışı ile başa çıkmak amacıyla oluşturulmuş bazı programlar sunulmuştur. Ertelemeye ilişkin ulusal alan yazını ve öğrenci-yetişkin profili karşılaştırmalı bir çalışmanın katkılarıyla tartışılmıştır.

Anahtar Kelimeler: Erteleme, erteleme türleri, bileşenleri, başa çıkma programları

\footnotetext{
${ }^{1}$ Doç. Dr., Bahçeşehir Üniversitesi, Eğitim Bilimleri Fakültesi,

${ }^{2}$ Prof. Dr., Orta Doğu Teknik Üniversitesi, Eğitim Bilimleri Bölümü,
} 
Procrastination: Types, Components, Demographic Effects, and Cultural Differences

Submitted by 07.03.2015 Accepted by 20.05.2015

\begin{abstract}
Procrastination refers to put off intended tasks to another time (Lay, 1986). The purpose of procrastination is to make one's life more pleasant, but it nearly always add stress, disorganization and failure. The idea underlying procrastination may be 'later is better' However, when tomorrow comes, the pattern resurfaces and the person excuses him/herself by promising that 'I will do it tomorrow'. Hence, procrastination can be called as 'tomorrow syndrome'. Research results have shown that procrastination should be overcome since engaging in procrastination lead to negative outcome along with negative affect on the individuals' psychological wellbeing. National literature follows international results. In this respect, in the present review, definitions of procrastination, types and components of procrastination are presented along with the treatment programs. The national literature on procrastination and prevalence of procrastination among students and adults in terms of cross-cultural results will also be discussed.
\end{abstract}

Key Words: Procrastination, types of procrastination, components, treatment programs. 


\section{Giriş}

'Modern çağın sorunlarından' biri olarak betimlenen erteleme, 'bugünün işini yarına bırakmak' olarak da ifade edilebilir (Ferrari, Johnson ve McCown, 1995). Erteleme yeni bir olgu değildir. Uzun bir tarihçesi olan ertelemenin bilimsel çalışma konusu olarak incelenmeye başlanması 30-40 yıl öncesine dayanmaktadır. Ertelemenin amacı kişinin hayatına kısa dönemli haz katmak gibi görünse de bu eğilimin davranışa dönüşmesi insan psikolojisi üzerinde çoğu zaman olumsuz etkiler bırakmaktadır (Clayton, 2000). Ertelemenin altında yatan düşünce 'ertesi gün daha iyi'dir. Ancak ertesi gün geldiğinde durum tekrarlanır ve kişi kendine yeniden 'bunu yarın yapacağım' sözü verir. Yaşanan bu kısır döngü nedeniyle erteleme ‘ertesi gün sendromu’ olarak da adlandırılır.

\section{Ertelemenin Tanımı}

Alan yazında ertelemeye ilişkin ortak bir tanım olmamasına karşın her tanımın ortak olarak 'geciktirme' kavramını içerdiği görülmektedir. Örneğin, Knaus (1998) ertelemeyi, önceliği olan bir işi daha sonraya bırakmak olarak tanımlamaktadır. Tuckman'ın (1991) erteleme tanımında, öz-düzenleme performansının yoksunluğu belirgin iken, Lay (1986) ertelemeyi gerekli olan amaçlara ulaşmayı erteleme olarak tanımlamaktadır. Tanımlar farklılaşsa da ortak özelliğinin önceliği daha az olan bir işi, önceliği fazla olan diğer bir işin önüne koymak olduğu söylenebilir. Bununla birlikte, ertelemenin görevi geciktirme ya da görevden kaçınma gibi sadece davranış boyutunun değil, bilişsel ve duygusal bileşenlerinin de olduğu gözden kaçmamaktadır (Uzun Özer, Demir ve Ferrari, 2013).

\section{Ertelemenin Bileşenleri}

Araştırmacılar ertelemenin tek bir yapıdan oluşmayıp farklı bileşenlerden oluştuğunu belirtmişlerdir (Solomon ve Rothblum, 1984). Buna göre, ertelemenin davranışsal bileşeni, görevin başlatılması, yürütülmesi ya da tamamlanması üzerine odaklanmaktadır (Ferrari, 1992). Bu durumda, yapılması planlanan işin gereğinden fazla zaman alması söz konusudur (Rothblum, Solomon ve Murakami, 1986). Buna göre, ertelemenin davranış boyutu yapılması planlanan işten kaçınılıp daha çok keyif alınan başka bir işin yapılmasıdır. Kişinin ders çalışmadan kaçınıp televizyon seyretmesi örneği ertelemenin davranış boyutuna örnek olarak gösterilebilir. Günümüze kadar yürütülen 'davranış' yönelimli çalışmalarda, ertelemenin değerlendirilmesi için yapılan işin miktarı ve erteleme sıklığına odaklanıldığı görülmektedir (Beck, Koons ve Milgrim, 2001). Erteleme davranışının belirlenmesine yönelik olarak yapılan 
bazı çalışmalarda öğrencilerin dönem ödevi teslim tarihine bakılırken (Tice ve Baumeister, 1997) bazı araştırmalarda uygulanan ölçeklerin araştırmacıya geri verilmesine kadar geçen süre (Lay, 1986), teslim zamanı (Moon ve Illingworth, 2005) ya da verilen görevin başlama ve bitiş saati arasında geçen süre değerlendirilmiştir (Senecal, Lavolie ve Koestner, 1997). Buna ek olarak, davranış yönelimli bazı araştırmacılar öz-düzenlemenin erteleme davranışını en güçlü yordayan davranış değişkeni olduğunu belirtmektedir (Howell, Watson, Powell ve Buro, 2006; Klassen, Krawchuk ve Rajani, 2008; Uzun Özer ve Sarıcaoglu, 2014; Van Eerde, 2003).

Ertelemenin bilişsel bileşeni, bireyler üzerinde olumsuz etkileri olmasına rağmen erteleme davranışına bilinçli olarak karar verme nedenlerine odaklanmaktadır (Karas ve Spada, 2009). Bu doğrultuda öz-yetkinlik, mükemmeliyetçi kişilik özelliği ya da rasyonel olmayan düşünce tarzları gibi bilişsel değişkenler erteleme davranışı çalışmalarında sıklıkla yer almıştır (Bridges ve Roig, 1997; Chabaud, Ferrand ve Maury, 2010; Sirois, 2004). Örneğin, Burka ve Yuen (1983) bireylerin erteleme davranışının doğasında, kırılgan özsaygıyı koruma amacı olduğunu vurgulamaktadır. Bandura (1986) başka bir yaklaşımla ertelemenin düşük öz-yeterlik sebebinden kaynaklandığını belirtmektedir. Araştırma bulguları, bu doğrultuda, erteleme davranışının öz-saygı ve öz-yeterlik inançları ile olumsuz yönde ilişkili olduğunu ortaya koymaktadır (Beck ve diğ., 2000; Ferrari, 1994; Ferrari, 2001; Ferrari ve Emmons, 1994; Sirois, 2004).

Ertelemenin duygusal bileşeni içermesi bazı araştırmacıların özellikle üzerinde durduğu bir konudur (örn., Solomon ve Rothblum, 1984). Buna göre, kişinin belli bir zamanda yapması gereken işi başlatamama, sürdürememe ya da tamamlayamama konusunda kişisel bir sıkıntı hissetmesi ertelemenin duygusal parçasını içermektedir. Bu yönde yapılan araştırmalar ertelemenin öznel rahatsızlığına odaklanmaktadır (Burka ve Yuen, 1983; Solomon ve Rothblum, 1984). Bu doğrultuda araştırmacılar erteleme davranışını olumsuz duygulara neden olan kaygı ve endişe ile ilişkilendirmişlerdir (Tuckman, 1991). Duygusal yönelimli araştırmacılar kaygı ve endişe duygusunun erteleme ile ilişkili olan en olumsuz duygu olduğunu vurgulamaktadır (Ferrari ve Tice, 2000; Uzun Özer, Demir ve Harrington, 2012).

Çalışma bulgularında görülen bu değişkenlik, ertelemenin tek bir faktöre bağlı olmadığını, işlerin daha sonraki zamana bırakılmasının çoklu nedenlere bağlı olabildiğini ortaya koymaktadır. $\mathrm{Bu}$ doğrultuda ertelemenin çoklu bileşenlerle incelenmesi son zamanlarda önem kazanmıştır (Uzun Özer, O’Callaghan, Bokszczanin, Ederer, ve Essau 
2014). Ancak alan yazı göz önünde bulundurulduğunda bu yönde yapılan çalışmanın sınırlı sayıda olduğu gözlemlenmektedir.

\section{Ertelemenin Türleri}

Alan yazında erteleme dört ana başlık altında toplanmaktadır. Bunlardan en yaygın olanı, sınavlara çalışma, ödevleri tamamlama gibi yapılması gereken akademik görevlerin yapılmaması veya son dakikaya birakılması olan akademik ertelemedir (academic procrastination, Solomon ve Rothblum, 1984). Günlük işleri programlamada zorlanma ve bu işleri zamanında yapmakta güçlük çekmeye ilişkin rutin işlerde erteleme (life routine procrastination, Lay, 1986); çatışma durumlarında ya da farklı seçeneklerle karşı karşıya kalındığında karar vermenin geciktirilmesini içeren karar vermeyi erteleme (decisional procrastination, Effert ve Ferrari, 1989; Ellis \& Knaus, 1977) ve kişinin hem karar vermeyi hem de yapması gereken işleri ertelemesini içeren kompulsif erteleme (compulsive procrastination, Ferrari, 1991) ertelemenin diğer türlerini oluşturmaktadır.

Alan yazında bulguların büyük çoğunluğu, ertelemenin özellikle akademik alanda en yüksek düzeyde olduğunu ortaya koymaktadır (Harriot ve Ferrari, 1996). Bazı araştırmacılar bu oranın \%95'lere ulaştığını belirtmektedir (Ellis ve Knaus, 1977; Steel, 2007). Araştırma bulguları, erteleme davranışının dersten çekilme ve düşük akademik başarı gibi akademik performans üzerinde olumsuz etkileri olmasına rağmen (Keller, 1968; Valentine, DuBois ve Cooper, 2004), öğrencilerin akademik görevlerini sıkılıkla daha sonraki bir tarihe ertelediklerini ya da o görevi yapmayı tamamen bıraktıklarını göstermektedir (Bishop Gallagher ve Cohen, 2000; Tan ve diğ., 2008).

Alan yazında bazı araştırmacıların ertelemeyi bir alışkanlık (örn., Ellis ve Knaus, 1977) bazılarınınsa bir kişilik özelliği olarak kabul ettiği görülmektedir (örn., Ferrari, 1991; Lay, 1986). Ancak görünen o ki, ertelemeye ilişkin çalışmaların büyük çoğunluğu, ertelemeyi olumsuz yönde ele almaktadır. Örneğin, Burka ve Yuen (1983) ve Ferrari (2001), ertelemeyi öz yetersizlik ya da tehdit altında hissedilen öz-saygının savunulması olarak açıklamaktadır. Bunun yanı sıra erteleme, yüksek düzeyde sağlık sorunları, (Sirois, Melia-Gordon ve Pychyl, 2003; Tice ve Baumeister, 1997), düşük akademik başarı (Carden, Bryant ve Moss, 2004; Steel, 2004), kaygının değişik oluşumları (Cassady ve Johnson, 2002; Chabaud ve diğ., 2010; Stöber ve Joormann, 2001), akılcı olmayan inançlar ve yöntemler (Beswick, Rothblum ve Mann, 1988; Schubert, Lilly ve Stewart, 2000) gibi olumsuz davranış ve sonuçlarla ilişkilendirilmektedir. Bu sebepten dolayı özellikle üniversite öğrencileri, üniversite rehberlik 
servislerine başvurarak bu davranışın sebep olduğu olumsuz durumlardan yakınmaktadır (Schouwenburg, Lay, Pychyl, \& Ferrari, 2004).

Diğer taraftan bazı araştırmacılar (örn., Choi ve Moran, 2009; König ve Kleninmann, 2004; Sigall, Kruglanski ve Fyock, 2000) ertelemeyi olumlu yönde ele alarak erteleme davranışı sergilemenin faydalı olabildiğini belirtmektedir. Örneğin, Pychyl, Lee, Thibodeau, ve Blunt (2000)'a göre, yapılacak işleri daha sonraya bırakmak oldukça akılcı ve bireylerin olumlu hissetmesini sağlayan bir yoldur. Bu durum özellikle yapmaktan hoşlanılmayan bir görev yerine yapmaktan hoşlanılan bir görevin yapılması durumunda gerçekleşir. Chu ve Choi (2005) ise öğrencilerin zaman baskısı etkisiyle daha başarılı olabildiklerini ve bu sebeple ertelemeyi özellikle tercih ettiklerini belirtmektedir. Bu doğrultuda araştırmacılar ertelemeyi kısa dönemli olumlu duyguların düzenleyicisi olarak açıklamaktadır (Tice ve Baumeister, 1997). Buna göre, öğrenciler arkadaşları ile zaman geçirmek gibi bir etkinliği tercih ettiklerinden sınavlara çalışmayı erteleyebilir. Benzer olarak, erteleme davranışı sergileyenlerin iyimser düşündüklerini, öğrenmeleri gereken konuları bir gecede öğrenebilecekleri ya da sınavın çok kolay olacağı gibi düşüncelerin olabileceği bulunmuştur (Sigall ve ark., 2000). Erteleyen kişilerin, erteleme davranışı sergilediklerinde olumsuz bir işten kaçınıp daha keyifli etkinlikler içinde olduklarından dolayı olumsuz duygularından bahsetmedikleri saptanmıştır (König ve Kleinmann, 2004; Pychyl ve ark., 2000).

\section{Bazı Demografik Değişkenlere göre Erteleme}

$\mathrm{Bu}$ güne kadar yapılan bazı araştırma bulguları ertelemenin yaş ve cinsiyet gibi demografik değişkenle olan ilişkisinde farklı sonuçlara ulaşmıştır. Erteleme düzeyinin kadın ve erkekler arasında anlamlı farklılığı olup olmadığını anlamak için çok sayıda çalışma yapılmasına karşın, kesin bir sonuca ulaşılamamıştır. Buna göre bazı araştırmacılar kadınların erkeklere oranla daha yüksek düzeyde erteleme davranışı sergilediğini ortaya koyarken (örn., Doyle ve Paludi, 1998; Pychyl, Coplan ve Reid, 2002; Solomon ve Rothblum, 1984) diğer bazı araştırmacılar bu durumun tersi yönde bulgulara ulaşmıştır (Milgram, Marshevsky, ve Sadeh, 1994; Senecal ve diğ., 1995; Uzun Özer, 2014). Bununla birlikte, alan yazında erteleme düzeyinin cinsiyete göre anlamlı farklılığı olmadığını gösteren çalışma bulguları da oldukça fazladır (örn., Ferrari, 1991; Ferrari, 2001; Kachgal, Hansen, ve Nutter, 2001; Schouwenburg, 1992). Karşılaştırmalı çalışmalar olmasa da farklı kültürlerden edinilen veriler ışığında bu bulgulardan çıkarılacak sonuç kültürel farklılığa işaret etmemekle birlikte, erteleme düzeyinin örneklemin özelliğine göre değişim gösterdiği yönündedir. Ertelemenin yaş ile olan ilişkisine 
bakıldığında, erteleme düzeyinin 20'li yaşlardan sonra arttığı ve kişilerde erteleme davranışı sergileme oranının yaş ilerledikçe azaldığı görülmektedir (Ferrari ve diğ., 1995). Bununla birlikte, ertelemenin farklı kültürlerde yürütülen çalışma bulguları, ertelemenin kültüre göre bir farklılığ olmadığına işaret etmektedir (Schouwenburg, 1992; Beswick ve ark., 1988; Senecal ve ark., 1995). Benzer olarak kültürler arası karşılaştırmalı yürütülen başka bir çalışmada da ertelemenin kültürel farklılığa işaret etmediğini ortaya koymuştur (Ferrari, DiazMorales, O'Callaghan ve Argumedo, 2007; Prohaska, Morill, Atiles, ve Perez, 2001).

\section{Ertelemenin Nedenleri}

Ertelemeye katkıda bulunan etmenler göz önünde bulundurulduğunda, bu kavramın tanımında olduğu gibi kuramcı ve araştırmacıların ulaştı̆̆1 ortak bir nokta olmadığ görülmektedir. Bugüne kadar kuramcılar erteleme nedenlerini farklı kuramsal yaklaşım ve modellerle açıklamaya çalışmışlardır (Dietz, Hofer ve Fries, 2007; Eun Hee, 2009; Seo, 2008). Buna göre, psikoanalitik kuramcılar erteleme nedenlerini, kaygıdan kaynaklanan kaçınma davranışı ile açıklarken; ertelemenin aşırı talepkâr ya da aşırı hoşgörülü anne-baba tutumuna karşı gösterilen bir tepkiden olduğunu belirtmektedirler (bknz, Ferrari ve diğg., 1995). Bu yönde yapılan araştırma bulgularının bu görüşü destekleyen sonuçlara ulaştığı görülmektedir (Ferrari, ve Emmons, 1994; Uzun Özer, 2009b). Bilişsel Davranışçı görüşü benimseyen kuramcılar, ertelemenin kişilerin sahip olduğu akılcı olmayan düşüncelerden kaynaklandığın belirtirken (Burka ve Yuen, 1983; Ellis ve Knaus, 1977, Uzun Özer ve diğ., 2013); davranışç1 görüşe göre erteleme kişilere kısa dönemli haz sağlayan öğrenilmiş bir davranıştır (Lamba, 1999). Akılcı Duygusal Davranış Yaklaşımını benimseyen kuramcılar ise ertelemenin duygu düşünce ve davranış örüntüsünü ortaya koymuşlardır. Örneğin, Uzun Özer, O’Callaghan, Bokszczanin, Ederer ve Essau (2014) akılcı duygusal davranış yaklaşımını temel alarak ertelemenin depresyon, mükemmeliyetçilik ve öz düzenleme ile olan yol analizi modelini önermişlerdir. Kuramsal yapıları temel alarak yapılmış araştırmalarda ertelemenin nedenleri farklı yönlerde ele alınmıştır (Kachgal ve diğ., 2001; Schowuenburg, Lay, Pychyl ve Ferrari, 2004). Çalışma bulguları ertelemenin nedenlerin, görevden hoşlanmama (Milgram, Sroloff ve Rosebaum, 1988), tembellik (Senecal, Lavolie ve Koestner 1997), sınav kaygısı (Cassady ve Johnson, 2002), düşük öz-saygı (Meyer, 2001), yetersiz öz-düzenleme (Klassen ve diğg., 2008), olumsuz değerlendirilme korkusu (Ferrari, 1992), öğrenilmiş çaresizlik (McKean, 1994), dişsal denetim odağı (Deniz, Traş ve Aydoğan, 2009), mükemmeliyetçi kişilik özelliği (Seo, 2008) ya da başarısızlık korkusu (Solomon ve Rothblum, 1984) olduğunu göstermiştir. 


\section{Erteleme ile Baş Etme Yolları}

Alan yazınında erteleme ve sebeplerine sıklıkla yer verilirken; bu davranışın azaltılmasına yönelik olarak yapılan çalışmaların sınırlı olduğu gözden kaçmamaktadır (Kutlesa, 1998; Schubert ve diğ., 2000). Erteleme nedenlerine yönelik olan araştırmaların sonuçları, birçok sorunu beraberinde getiren ertelemenin üstesinden gelinmesinin kaçınılmaz olduğunu göstermiş ve bu doğrultuda ertelemenin azaltılmasına yönelik bazı uygulama önerilerinde bulunmuştur (Ferrari, 2010; Lay, 2004; Wadkins, 1999). Buna göre, bir grup araştırmacı (Walker, 2004) grupla psikolojik danışma uygulamalarının ertelemenin üstesinden gelmeye yönelik olarak faydalı bir uygulama olabileceğini önerirken, Mandel (2004) bireyle psikolojik danışma uygulamaları yapılmasını önermektedir. Benzer olarak, Van Essen, Ven Del Heuvel ve Ossebaard (2004) zaman-kontrolü derslerinin ve Van Horebeek, Michielsen, Neyskens, ve Depreeuw, (2004) eğitim gruplarının ertelemenin azaltılması amacıyla kullanılacak etkili yöntemlerden olduğunu vurgulamıştır.

Alan yazında, Ellis ve Knaus’un (1977) bilişsel-davranışçı kuram doğrultusunda geliştirdikleri, mükemmeliyetçilik, öfke/düşmanlık, tahammülsüzlük ve kendini aşağılamaya yönelik tutumların kontrol edilmesi yoluyla uygulanan programlar bulunmaktadır (Academic Skill Center, 2004). Bunun yanı sıra, Schubert ve diğerleri (2000) tarafından geliştirilen, iki aşama ve altı haftadan oluşan, yapılandırılmış bir programın uygulaması da görülmektedir. $\mathrm{Bu}$ program çerçevesinde erteleme ile yüksek düzeyde ilişkili olan görevden hoşlanmama, değerlendirilme kaygısı, bağımlılık, mükemmeliyetçilik, rasyonel olmayan inançlar, öğrenilmiş çaresizlik ve düşük öz-saygı üzerinde durulmuştur. Benzer olarak, Uzun Özer ve diğerleri (2013) akılcı duygusal davranış kuramı doğrultusunda uyguladıkları her biri 90 dakikadan oluşan beş oturumluk grupla psikolojik danışma uygulamalarının ertelemeyi azaltmaya ilişkin etkili olabildiğini rapor etmişlerdir. Araştırma çerçevesinde kullanılan öntest, son-test karşılaştırmalı desen, ertelemeye ilişkin rasyonel olmayan düşüncelerin çürütülmesi ve bunların yerine alternatiflerinin bulunması yoluyla uygulanan programın etkinliğini ortaya koymuştur.

\section{Türkiye’de Erteleme Alanında Yapılan Çalışmalar}

Ülkemizde erteleme alanında yapılan çalışmalar on yıl öncesine dayanmaktadır. Ertelemeye ilişkin ilk araştırma çalışmaları yüksek lisans tezi kapsamında başlamış (Çakıcı, 2003) ve hız alarak (Akbay, 2009; Akkaya, 2007; Aydoğan, 2008;), doktora tezleriyle (örn., Balkıs, 2006, Uzun Özer, 2010) devam etmiştir. Daha sonra, erteleme davranışını azaltmaya yönelik olarak 
uygulanan programlar (Uzun Özer ve diğ., 2013) ve test edilen kuramsal modeller (Balkıs, 2013; Kandemir, 2014) erteleme çalışmalarında yerini almıştır. Üniversite öğrencilerinin akademik erteleme davranışı üzerine yoğunlaşan çalışma bulguları, öz yeterlik algısı, akademik yükleme stilleri ve akademik güdülenmenin akademik ertelemeyi anlamlı düzeyde yordadığı (Akbay, 2009); sorumluluk kişilik özelliği, başarı yönelimi, akademik öz-yeterlik inancı ve benlik saygısının akademik erteleme ile neden-sonuç ilişkisi içinde doğrudan ve dolaylı şekilde açıklandığını ortaya koyarken; akademik ertelemenin benlik saygısı, öz yeterlik algısı ile olumsuz ve yüksek düzeyde ilişkili olduğu (Uzun Özer ve diğ., 2012; Uzun Özer, Saçkes ve Tuckman, 2013) bulunmuştur. Balkıs (2006), üniversite öğrencilerinde erteleme eğiliminin rasyonel karar verme ve düşünme stilleri ile olumsuz yönde; bağıml, kaçıngan ve anlık karar verme stilleri ile olumlu yönde ilişkili olduğunu rapor etmiştir. Uzun Özer (2011) tarafından gerçekleştirilen kesitsel çalışmada lise, lisans ve lisansüstü öğrencilerin erteleme düzeyleri ve erteledikleri akademik görevler karşılaştırılmıştır. Bulgular, lisans öğrencilerinin erteleme davranışı sergileme düzeylerinin lise öğrencilerinden ve lisansüstü eğitimlerine devam eden öğrencilerden daha yüksek düzeyde olduğunu gösterirken; lise ve lisans öğrencileri akademik alanda en fazla sınavlara hazırlanmayı; oysa lisansüstü öğrenciler dönem ödevlerini tamamlamayı ertelediklerini rapor etmişlerdir. Uzun Özer ve diğerleri (2013) tarafından yapılan deneysel çalışma bulgularıysa akılcı duygusal davranış yaklaşımı ile kullanılan 'erteleme davranışı ile başa çıkma' programının öğrencilerde ertelemenin azaltılmasına yardımcı olduğunu ortaya koymuştur. Erteleme, yakın zamanda, kültürler arası karşılaştırma çalışmalarında yerini almıştır (Uzun Özer ve diğ., 2014). Buna göre, İngiltere'de eğitimlerine devam eden öğrencilerle yapılan karşılaştırma Türk öğrencilerin daha az düzeyde erteleme davranışı sergilediklerini rapor etmeleriyle sonuçlanmıştır (Uzun Özer ve diğ., 2013). Bu karşılaştırma çalışmasında cinsiyete ilişkin anlamlı bir farklılık bulunmamasına karşın, ulusal düzeyde yapılan çalışmalarda erkek öğrencilerin kız öğrencilere oranla yüksek düzeyde erteleme davranışı sergiledikleri belirtilmiştir (Balkıs ve Duru, 2009; Uzun Özer ve diğ., 2009). Benzer olarak ülkemizde de 20'li yaşların hakim olduğu üniversite eğitimi sırasında erteleme düzeyinin (Ferrari, Uzun Özer ve Demir, 2009; Uzun Özer, 2011) ergenler (Uzun Özer, 2009a) ve yetişkinlerdeki (Ferrari ve diğ., 2009) erteleme düzeyine göre en üst seviyede olduğu görülmektedir. 


\section{Sonuç ve Öneriler}

Erteleme, önceliği daha az olan bir iş ya da görevin, önceliği olan bir iş ya da görevin önüne koyulması olarak tanımlanabilir. Çoğu zaman olumsuz sonuçlarla anılan bu davranışın altında yatan düşünce 'bunu yapmak için yarın daha iyi' fikridir. Ancak yarın geldiğinde koşullar umulduğu kadar uygun olmayabilir, erteleme durumu tekrarlanır ve kişi kendine yeniden 'Bunu yarın yapacağım' sözü verir. Bu döngü ertelemenin 'ertesi gün sendromu' olarak da adlandırılmasını sağlar (Knaus, 2002).

Alan yazında, ertelemenin gerek tanımında gerekse türlerinde farklılıklar olduğu görülmektedir. $\mathrm{Bu}$ doğrultuda tüm erteleme tanımları 'geciktirme' kavramını ortak olarak içerse de, yaklaşımlarla bağlantılı olarak farklı bileşenlere sahip olduğu açıktır. Ertelemeye yönelik kuramların da vurguladığı gibi bireyler farklı sebeplerle eteleme davranışı sergileyebilirler ancak bu davranışın iyileştirilmesi bireylerin psikolojik sağlığı açısından önemlidir. Ertelemeye ilişkin alan yazını ertelemenin olumsuz sonuçlara neden olduğu görüşünü benimsediğinden; bu davranışın kontrol edilmesi ya da üstesinden gelinmesinin gerekliliği üzerinde sık sık durmuştur. Alan yazında bu yönde yapılan çalışmalar sınırlı olmasından dolayı, ertelemenin derinlemesine anlaşılmasına ilişkin daha fazla sayıda çalışmaya ihtiyaç duyulmaktadır. Bunun yanı sıra ertelemenin tek bileşenden oluşmadığı sonucu göz önünde bulundurulduğundan bu kavramın duygusal, bilişsel ve davranışsal boyutları karşılayacak farklı değişkenlerle incelenmesi fayda sağlayacaktır. Erteleme davranışının bireyler üzerinde olumsuz etkileri değerlendirildiğinde bu davranışın üstesinden gelinmesine yönelik olarak hazırlanacak kuramsal program ve uygulamalara ihtiyaç duyulmaktadir.

Ulusal alan yazında erteleme davranışına ilişkin çalışmalar olmasına rağmen, bu davranışın temelini oluşturan bazı kavram ve kuramlara ilişkin bilginin yetersiz olduğu düşünülmektedir. Bu doğrultuda bu çalışmada ertelemeye ilişkin kavram ve kuramlar, tür ve oluşumları çerçevesinde derlenerek sunulmuştur. Bu çalışmanın ulusal alan yazında erteleme davranışına ilişskin derleme boşluğunu dolduracağı beklenmektedir. Bu doğrultuda ertelemeye ilişskin ulusal ve uluslararası başlatılan önemli çalışma ve bu çalışmaların bulgularına yer verilmiştir. 


\section{Kaynakça}

Academic Skills Center, (2004). Procrastination is the thief of time. 12 Ağustos, 2004 tarihinde www.sas.calpdy.edu/asc/ssl/procrastination.html adresinden elde edilmiștir.

Akbay, S., E. (2009). Cinsiyete göre üniversite ögrencilerinde akademik erteleme davranışı: Akademik güdülenme, akademik özyeterlik ve akademik yükleme stillerinin rolü. (Yayımlanmamış Yüksek Lisans Tezi). Mersin: Mersin Üniversitesi. https://tez.yok.gov.tr/UlusalTezMerkezi/tezSorguSonucYeni.jsp (253522) adresinden elde edilmiştir.

Akkaya, E. (2007). Academic procrastination among faculty of education students: The role of gender, age, academic achievement, perfectionism and depression. (Yayımlanmamış Yüksek Lisans Tezi). Ankara: Orta Doğu Teknik Üniversitesi.

Aydoğan, D. (2008). Akademik erteleme davranışının benlik saygısl, durumluk kaygl ve özyeterlik ile açıklanabilirliği. (Yayımlanmamış Yüksek Lisans Tezi). Gazi Üniversitesi, Ankara: https://tez.yok.gov.tr/UlusalTezMerkezi/tezSorguSonucYeni.jsp (218067) adresinden elde edilmiştir.

Balkıs, M. (2006). Öğretmen adaylarının davranışlarındaki erteleme eğiliminin düşünme ve karar verme tarzları ile ilişkisi. (Yayımlanmamış Doktora Tezi). Dokuz Eylül Üniversitesi, İzmir: https://tez.yok.gov.tr/UlusalTezMerkezi/tezSorguSonucYeni.jsp (189853) adresinden elde edilmiştir.

Balkıs, M. (2013). Academic procrastination, academic life satisfaction and academic achievement: The mediation role of rational beliefs about studying. Journal of Cognitive and Behavioral Psychoterapies, 13(1), 57-74.

Balkıs, M., ve Duru, E. (2009). Prevalance of academic procrastination among pre-service teachers, and its relationship with demographics and individual preferences. Journal of Theory and Practice in Education, 5(1), 18-32.

Bandura, A. (1986). Social foundations of thought and action: A social cognitive theory NJ: Prentice-Hall.

Beck, B. L., Koons, S. R., ve Milgrim, D. L. (2001). Correlates and consequences of behavioral procrastination: The effects of academic procrastination, selfconsciousness, self-esteem, and self-handicapping. Journal of Social Behavior \& Personality, 16(1), 3-11.

Beswick, G., Rothblum, E. D. ve Mann, L. (1988). Psychological antecedents of student procrastination. Australian Psychologist, 23(2), 207-217.

Bishop, J. B., Gallagher, R. P. ve Cohen, D. (2000). College students’ problems: Status, trends, and research. İçinde D. H. Davis, K (Ed.), College counseling: Issues and strategies for a new millennium: American Counseling Association.

Bridges, K. R. ve Roig, M. (1997). Academic procrastination and irrational thinking: A reexamination with context controlled. Personality and Individual Differences, 22(6), 941-944.

Burka, J. B. ve Yuen, L. M. (1983). Procrastination: Why do you do it, what to do about it. CA: Addison-Wesley Publishing Company.

Carden, R., Bryant, C. ve Moss, R. (2004). Locus of control, test anxiety, academic procrastination, and achievement among college students. Psychological Reports, 95(2), 581-582.

Cassady, J. C. ve Johnson, R. E. (2002). Cognitive test anxiety and academic performance. Contemporary Educational Psychology, 27(2), 270-295. 
Chabaud, P., Ferrand, C. ve Maury, J. (2010). Individual diffrerences in undergraduate student athletes: The roles of perfectionism and trait anxiety perception of procrastination behavior. Social Behavior \& Personality: An International Journal, 38(8), 1041-1056.

Choi, J. N. ve Moran, S. V. (2009). Why not procrastinate? Development and validation of a new active procrastination scale. Journal of Social Psychology, 149(2), 195-212.

Chu, A. H. C., ve Choi, J. N. (2005). Rethinking procrastination: Positive effects of "Active" procrastination behavior on attitudes and performance. Journal of Social Psychology, 145(3), 245-264.

Clayton, E., T. (2000). Psychological self-help (4. Böl) 18 Nisan, 2003’te, http://www.mentalhelp.net/psyhelp/chap4/chap4r.htm adresinden elde edilmiştir.

Çakı1, D. Ç. (2003). Lise ve üniversite ögrencilerinde genel ve akademik erteleme davranışının incelenmesi. (Yayımlanmamış Yüksek Lisans Tezi). Ankara: Ankara Üniversitesi. $\quad$ https://tez.yok.gov.tr/UlusalTezMerkezi/tezSorguSonucYeni.jsp (205276) adresinden elde edilmiştir.

Deniz, M. E., Traş, Z. ve Aydoğan, D. (2009). An Investigation of academic procrastination, locus of control, and emotional intelligence. Educational Sciences: Theory \& Practice, 9(2), 623-632.

Dietz, F., Hofer, M. ve Fries, S. (2007). Individual values, learning routines and academic procrastination. British Journal of Educational Psychology, 77(4), 893-906.

Doyle, J. A. ve Paludi, M. A. (1998). Sex and gender: The human experience. Boston: McGrow Hill.

Effert, B. R. ve Ferrari, J. R. (1989). Decisional Procrastination - Examining PersonalityCorrelates. Journal of Social Behavior and Personality, 4(1), 151-156.

Ellis, A.,ve Knaus, W. (1977). Overcoming procrastination. NY: Signet.

Eun Hee, S. E. O. (2009). The relationship of procrastination with a mastery goal versus an avoidance goal. Social Behavior \& Personality: An International Journal, 37(7), 911919.

Ferrari, J. R. (1991). Compulsive procrastination: Some self-reported characteristics. Psychological Reports, 68(2), 455-458.

Ferrari, J. R. (1992). Procrastinators and perfect behavior: An exploratory factor analysis of self-presentation, self-awareness, and self-handicapping components. Journal of Research in Personality, 26, 75-84.

Ferrari, J. R. (1994). Dysfunctional procrastination and its relationship with self-esteem, interpersonal dependency, and self-defeating behaviors. Personality and Individual Differences, 17(5), 673-679.

Ferrari, J. R. (2001). Procrastination and attention: Factor analysis of attention deficit, boredomness, intelligence, self-esteem, and task delay frequencies. Journal of Social Behavior \& Personality, 16, 185-196.

Ferrari, J. R. (2010). Still procrastinating? The no regrets guide to getting it done. New York: Wiley.

Ferrari, J. R., Diaz-Morales, J. F., O'Callaghan, J., Diaz, K., \& Argumedo, D. (2007). Frequent behavioral delay tendencies by adults: International prevalence rates of chronic procrastination. Journal of Cross-Cultural Psychology, 38(4), 458-464.

Ferrari, J. R., ve Emmons, R. A. (1994). Procrastination as revenge: Do people report using delays as a strategy for vengeance? Personality and Individual Differences, 17(4), 539-544.

Ferrari, J. R., Johnson, J. L. ve McCown, W. G. (1995). Procrastination and task avoidance: Theory research, and treatment. NY: Plenum Press. 
Ferrari, J. R. ve Tice, D. M. (2000). Procrastination as a self-handicap for men and women: A task-avoidance strategy in a laboratory setting. Journal of Research in Personality, 34(1), 73-83.

Ferrari, J. R. Uzun Özer, B., \& Demir, A. (2009). Chronic procrastination among Turkish adults: Exploring decisional, avoidant, and arousal styles. Journal of Social Psychology, 149(3), 302-308.

Harriot, J., ve Ferrari, J. R. (1996). Prevalence of procrastination among sample of adults. Psychological Reports, 78, 611-616.

Howell, A. J., Watson, D. C., Powell, R. A., ve Buro, K. (2006). Academic procrastination: The pattern and correlates of behavioural postponement. Personality and Individual Differences, 40(8), 1519-1530.

Kachgal, M. M., Hansen, L. S., ve Nutter, K. J. (2001). Academic procrastination prevention/intervention strategies and recommendations. Journal of Developmental Education, 25(1), 14-20.

Kandemir, M. (2014). The predictors of academic procrastination: Responsibility, attributional styles regarding sucsess/failure, and beliefs in academic self-efficacy. Education and Science, 39(171), 99-114.

Karas, D. ve Spada, M. M. (2009). Brief cognitive-behavioural coaching for procrastination: A case series. Coaching: An International Journal of Theory, Research \& Practice, 2(1), 44-53.

Keller, F. S. (1968). “Good-Bye teacher...” Journal of Applied Behavior, 1, 79-89.

Klassen, R. M., Krawchuk, L. L. ve Rajani, S. (2008). Academic procrastination of undergraduates: Low self-efficacy to self-regulate predicts higher levels of procrastination. Contemporary Educational Psychology, 33(4), 915-931.

Knaus, W. J. (1998). Do it now! Break the procrastination habit. New York: John Wiley \& Sons, Inc.

Knaus, W. (2002). The Procrastination Workbook. Oakland, CA: New Harbinger Publication Inc.

König, C. J. ve Kleninmann, M. (2004). Business before pleasure: No strategy for procrastinators? Personality and Individual Differences, 37, 1045-1057.

Kutlesa, N. (1998). Effect of group counseling with university students who complain of procrastination. Unpublished Master's Thesis. London: University of Western Ontario. http://www.collectionscanada.gc.ca/obj/s4/f2/dsk2/ftp01/MQ30727.pdf adresinden elde edilmiştir.

Lamba, G. (1999). Effects of gender-role and self-efficacy on academic procrastination in college students. (Unpublished Master's Thesis). Truman State University, Missouri.

Lay, C. H. (1986). At least my research article on procrastination. Journal of Research in Personality, 20, 474-495.

Lay, C. H. (2004). Some basic elements in counseling procrastinators. İçinde H. C. Schouwenburg, C. H. Lay, T. A. Pychyl, \& J. R. Ferrari (Ed.), Procrastination and task avoidance: Theory, research, and treatment (pp. 43-58). New York: Plenum Press.

Mandel, H. P. (2004). Constructive confrontation: Cognitive behavior therapy with one type of procrastinating underachiever. In H. C. Schouwenburg, C. H. Lay, T. A. Pychyl ve J. R. Ferrari (Ed.), Counseling the procrastinator in academic setting (pp. 119-131). Washington DC: American Psychological Association. 
McKean, J. K. (1994). Using multiple risk factors to assess the behavioral, cognitive, and affective effects of learned helplessness. The Journal of Psychology:Interdisciplinary and applied, 128(2), 177-123.

Meyer, C. L. (2001). Academic procrastination and self handicapping: Gender differences in response to noncontingent feedback. Journal of Social Behavior \& Personality, 16(1), 87-122.

Milgram, N., Marshevsky, S. ve Sadeh, A. (1994). Correlates of academic procrastination: Discomfort, task aversiveness, and task capability. The Journal of Psychology, 129(1), 145-155.

Milgram, N. A., Sroloff, B. ve Rosebaum, M. (1988). The procrastination of everyday life. Journal of Research in Personality, 22(197-212).

Moon, S. M. ve Illingworth, A. J. (2005). Exploring the dynamic nature of procrastination: A latent growth curve analysis of academic procrastination. Personality and Individual Differences, 38, 297-309.

Prohaska, V., Morill, P., Atiles, I. ve Perez, A. (2001). Academic procrastination by nontraditional students. Journal of Social Behavior \& Personality, 16(1), 125-134.

Pychyl, T. A., Coplan, R. J. ve Reid, P. A. M. (2002). Parenting and procrastination: Gender differences in the relations between procrastination, parenting style and self worth in early adolescence. Personality and Individual Differences, 33, 271-285.

Pychyl, T. A., Lee, J. M., Thibodeau, R. ve Blunt, A. (2000). Five days of emotion: An experience sampling study of undergraduate student procrastination. Journal of Social Behavior \& Personality, 15(5), 239-254.

Rothblum, E. D., Solomon, L. J. ve Murakami, J. (1986). Affective, cognitive, and behavioral differences between high and low procrastinators. Journal of Counseling Psychology, 33(4), 387-394.

Schouwenburg, H., C. (1992). Procrastinators and fear of failure: An exploration of reasons for procrastination. European Journal of Personality, 6, 225-236.

Schouwenburg, H. C. (2004). Procrastination in academic settings: general introduction. İçinde C. H. H. C. Schouwenburg, T. A. P. Lay ve J. R. Ferrari (Eds.), Counseling the procrastinator in academic settings (pp. 3-17). Washington DC: American Psychological Association.

Schowuenburg, H. C., Lay, C. H., Pychyl, T. A. ve Ferrari, J. R. (2004). Counseling the procrastinator in academic settings. Washington, DC: American Psychological Association.

Schubert, W., Lilly, J. ve Stewart, D. W. (2000). Overcoming the powerlessness of procrastination. Guidance and Counseling, 16(1), 39-43.

Senecal, C., Koestner, R., ve Vallerand, R. J. (1995). Self-regulation and academic procrastination. Journal of Social Psychology, 135(5), 607-619.

Senecal, C., Lavoie, K. ve Koestner, R. (1997). Trait and situational factors in procrastination: An interactional model. Journal of Social Behavior \& Personality, 12(4), 889-903.

Seo, E. H. (2008). Self-efficacy as a mediator in the relationship between self-oriented perfectionism and academic procrastination. Social Behavior \& Personality: An International Journal, 36(6), 753-764.

Sigall, H., Kruglanski, A., ve Fyock, J. (2000). Wishful Thinking and Procrastination. Journal of Social Behavior and Personality, 15(5), 283-296.

Sirois, F. M. (2004). Procrastination and intentions to perform health behaviors: The role of self-efficacy and the consideration of future consequences. Personality and Individual Differences, 37(1), 115-128. 
Sirois, F. M., Melia-Gordon, M. L. ve Pychyl, T. A. (2003). "I'll look after my health, later": An investigation of procrastination and health. Personality and Individual Differences, 35(5), 1167-1184.

Solomon, L. J. ve Rothblum, E. D. (1984). Academic procrastination: Frequency and cognitive-behavioral correlates. Journal of Counseling Psychology, 31(4), 503-509.

Steel, P. (2004). The nature of procrastination(A Meta Analytic Study). http://www.ucalgary.ca/mg/research/media/2003_07.pdf adresinden 18, May1s 2004, tarihinde elde edilmiştir.

Steel, P. (2007). The nature of procrastination: A meta-analytic and theoretical review of quintessential self-regulatory failure. Psychological Bulletin, 133(1), 65-94.

Stöber, J. ve Joormann, J. (2001). Worry, procrastination, and perfectionism: Differentiating amount of worry, pathological worry, anxiety, and depression. Cognitive Therapy \& Research, 25(1), 49.

Tan, C. X., Ang, R. P., Klassen, R. M., Lay See, Y., Wong, I. Y. F., Huan, V. S. ve diğerleri (2008). Correlates of academic procrastination and students' grade goals. Current Psychology, 27(2), 135-144.

Tice, D. M. ve Baumeister, R. F. (1997). Longitudinal study of procrastination, performance, stress, and health: The cost and benefits of dawdling. Psychological Science, 8(6), 454-458.

Tuckman, B. W. (1991). The development and concurent validity of the procrastination scale. Educational \& Psychological Measurement, 51, 473- 481.

Uzun Özer, B. (2009a). Bir grup ergende erteleme davranışı: Sıklığı, olası nedenleri ve umudun rolü. Turkish Psychological Counselling and Guidance Journal, 32, 12-19.

Uzun Özer, B. (2009b). Algllanan anne-baba tutumunun akademik erteleme davranışına etkisi. Türkiyede çocuk yetiştirme: Yaklaşımlar, yöntem, sorunlar, çözümler. Vi. Ulusal Çocuk Kültürü Kongresi Bildirileri, ss 167-178. Ankara.

Uzun Özer, B. (2010). A Path analytic study of procrastination: Testing cognitive, affective, and behavioural components. (Unpublished Doctorate Thesis). Ankara: Middle East Technical University.

Uzun Özer, B. (2011). A cross sectional study on procrastination: Who procrastinate more? 2011 International Conference of Education, Research, and Innovation Conference, Singapore.

Uzun Özer, B. (2014). Psychometric properties of Adult Inventory of Procrastination in a Turkish culture. Journal of Adult Development, 21, 43-47.

Uzun Özer, B., Büyükgöze Kavas, A., O’Callaghan, J. ve Essau, A. C. (2014). Yes, no, maybe. University \& Collage Counseling Journal, http://www.aucc.uk.com/Publications/ adresinden elde edilmiştir.

Uzun Özer, B., Demir, A. ve Ferrari, J. R. (2009). Exploring academic procrastination among Turkish students: Possible gender differences in prevalence and reasons. Journal of Social Psychology, 149(2), 241-257.

Uzun Özer, B., Demir, A. ve Ferrari, J. R. (2013). Reducing of academic procrastination through a group treatment program: A Pilot Study. Journal of Rational EmotiveCognitive Behavioural, 31(3), 127-135.

Uzun Özer, B., Demir, A. ve Harrington, N. (2012). Psychometric properties of Frustration Discomfort Scale in a Turkish sample. Psychological Reports: Measures \& Statistics, 111(1), 117-128.

Uzun Özer, B., O’Callaghan, J., Bokszczanin, A., Ederer, E. ve Essau, C. A. (2014). Dynamic interplay of depression, perfectionism, and self-regulation on procrastination. British 
Journal of Guidance and Counselling, 43(3), 309-319. Doi: 10.1080/03069885.2014.896454

Uzun Özer, B., Saçkes, M., \& Tuckman, W. B. (2013). Psychometric properties of the Tuckman Procrastination Scale in a Turkish sSample. Psychological Reports: Measurement and Assessment, 113(3), 874-884.

Uzun Özer, B. ve Sarıcaoglu, H. (2014). An experimental study on academic procrastination: Effects of weekly homework. International Journal of Psycho-Educational Sciences, 5(5), 1-7.

Valentine, J. C., DuBois, D. L. ve Cooper, H. (2004). The relations between self-beliefs and academic achievement: A meta-analytic review. Educational Psychologist, 39(2),111133.

Van Eerde, W. (2003). A meta-analytically derived nomological network of procrastination. Personality and Individual Differences, 35, 1401-1418.

Van Essen, T., Ven Den Heuvel, S. ve Ossebaard, M. (2004). A student course on selfmanagement for procrastinators. İçinde H. C. Schouwenburg, C. H. Lay, T. A. Pychyl \& J. R. Ferrari (Ed.), Counseling the procrastinator in academic settings (pp. 59-74). Washington DC: American Psychological Association.

Van Horebeek, W., Michielsen, S., Neyskens, A. ve Depreeuw, E. (2004). A cognitivebehavioral approaching in group treatment of procrastinators in an academic setting. İçinde H. C. Schouwenburg, C. H. Lay, T. A. Pychyl ve J. R. Ferrari (Ed.), Counseling the procrastinator in academic settings (pp. 105-118). Washington DC: American Psychological Association.

Wadkins, T. (1999). The relation between self-reported procrastination and behavioral procrastination. (Unpublished Doctoral Dissertation). University of Nebraska, Nebraska.

Walker, L. S. (2004). Overcoming the patterns of powerlessness that lead to procrastination. İçinde H. C. Schouwenburg, C. H. Lay, T. A. Pychyl ve J. R. Ferrari (Ed.), Counseling the procrastinator in academic settings. Washington DC: American Psychological Association. 